\title{
EDUCAÇÃO AMBIENTAL E EDUCAÇÃO FÍSICA: POSSIBILIDADES PARA A FORMAÇÃO DE PROFESSORES'
}

\author{
DRA. SORAYA CORRÊA DOMINGUES \\ Doutora em Educação Física pela Universidade Federal de Santa Catarina \\ Professora de Educação Física do Centro Universitário Campos de Andrade \\ (Curitiba - Paraná - Brasil) \\ e-mail: socodol I@hotmail.com
}

\section{DR. ELENOR KUNZ}

Doutor em Educação Física pelo Instituto de Ciências do Esporte pela Universität Hannover Professor do Departamento de Educação Física da Universidade Federal de Santa Catarina

(Florianópolis - Santa Catarina - Brasil)

e-mail: kunz@cds.ufsc.br

\author{
DRA. LÍSIA COSTA GONÇALVES DE ARAÚJO \\ Educação Física pela Universidade Federal de Santa Catarina \\ Professora de Educação Física da Universidade do Vale de Itajaí \\ (Florianópolis - Santa Catarina - Brasil) \\ e-mail: lisiacg@hotmail.com
}

\begin{abstract}
RESUMO
Este trabalho está entre os que estudam a Educação Ambiental e a Educação Física. Através da análise teórica de documentos, livros e artigos buscamos evidenciar no campo da Educação Ambiental os objetivos, princípios e diretrizes construídos historicamente, e identificamos na Formação de Professores em Educação Física os limites e as possibilidades para desenvolver trabalho pedagógico de acordo com os princípios da Educação Ambiental. Indicamos que essa aproximação entre a Educação Ambiental e a Formação de Professores em Educação Física pode ser pensada a partir da compreensão crítica de conteúdos e formas específicas da Educação Física.
\end{abstract}

PALAVRAS-CHAVE: Educação ambiental; formação de professores; educação fisica; parâmetros curriculares.

I. Este artigo teve apoio da CAPES (edital 0 I/ppgef/2009 e número do processo 23080.00793 I/200938), pois ele é parte dos estudos de tese da autora Soraya Corrêa Domingues que recebe apoio com bolsa de Doutorado no Curso de Pós-graduação em Educação Física da Universidade Federal de Santa Catarina. 


\section{INTRODUÇÃO}

Nos diversos espaços de atuação profissional é possível perceber crescente interesse pela Educação Ambiental. No processo formal de educação, por exemplo, as diretrizes nacionais indicam a necessidade de implantação da Educação Ambiental de modo contínuo e transversal (BRASIL, 1998) incentivando o trato sobre este conhecimento na área da Educação Física escolar. Em outros espaços fora da escola é possível perceber também que existe crescente atuação profissional da Educação Física de modo direto e indireto em atividades que proporcionam estreita relação entre a natureza e o ser humano. O estudo de Inácio (2006) chama atenção para o número significativo de profissionais e público, em geral, envolvido em atividades radicais, esportes de aventura, caminhadas, que apresentam.

Na área da Educação Física brasileira, a produção do conhecimento, vem também demonstrando crescente interesse por temas como corpo, cultura, natureza, turismo e lazer. Este movimento pode ser percebido a partir da revisão de periódicos, teses e dissertações ${ }^{2}$. Esses trabalhos, em geral, inclinam para o aprofundamento sobre as atividades físicas na natureza, seus impactos, necessidades, possibilidades para praticantes e para o campo de atuação da Educação Física.

Sobre questões mais gerais do tema Meio Ambiente e Educação Física, autores como Leite e Caetano (2004) abordam o caráter ambientalista ${ }^{3}$ de atividades desenvolvidas na natureza. Para eles são necessários mais estudos no campo da Educação Física relacionado ao Saber Ambiental ${ }^{4}$, e devem estar ancorados na perspectiva de uma Educação Ambiental.

Entre os autores pesquisados, especificamente no campo da Formação de Professores em Educação Física, alguns chamam atenção para a necessidade de trabalhar a questão ambiental. Encontramos em Marinho e Inácio (2007) contribuições relevantes para a área da Educação Física mais relacionada ao Lazer.

2. Foram utilizadas como filtro as palavras-chave: Ambiental, meio ambiente, educação ambiental e natureza. Nos periódicos digitalizados e disponibilizados on-line em seus respectivos sítios: Movimento, LICERE e Motrivivência. Também a RBCE digitalizada em CD até o ano de 2005 e no sítio próprio on-line nos anos subsequentes. Foram pesquisadas teses e dissertações do domínio público dia 17 de novembro de 2009. <http://www.dominiopublico.gov.br/pesquisa/PesquisaObraForm.jsp >

3. Movimento Ambientalista é definido pela autora Gohn (2006) como um dos chamados "novos movimentos sociais", pois eles apresentam características, não mais apenas ligadas aos interesses de uma classe ou de um sindicato, mas sim um movimento que está em todas as classes, pois diz respeito ao interesse de todos independente de participação ou identificação de um determinado grupo, é a luta pela defesa da vida planetária.

4. Termo utilizado pelo autor Leff (200I). 
Identificamo-nos com esses autores no que diz respeito a ênfase nos estudos sobre meio ambiente e neste texto buscamos trabalhar a temática da Educação Ambiental na Educação Física, especificamente sobre formação de professores. Já que segundo os autores citados esta temática é relevante socialmente e ainda pouco explorada. Partimos, então, da análise de referenciais teóricos sobre a Educação Ambiental e a caracterização da área de Formação de Professores em Educação Física identificando alguns elementos sobre conteúdo e forma, relevantes para pensar a relação entre os princípios e fundamentos de possibilidades pedagógicas entre a Educação Ambiental e a Formação de Professores em Educação Física.

Foram analisados vários documentos sobre a Educação Ambiental, como tratados, cartas e dossiês de fóruns mundiais, nacionais e regionais, publicações em artigos de periódicos, revistas em geral, programas de televisão e livros. Nestes documentos buscamos compreender os problemas e soluções ambientais e princípios da Educação Ambiental.

Quanto a Formação de Professores em Educação Física buscamos analisar algumas características de modo que nos permita entender a realidade da formação de professores, destacando seus limites e possibilidades para desenvolver o trabalho pedagógico a partir dos princípios da Educação Ambiental.

\section{OS PROBLEMAS AMBIENTAIS E A EDUCAÇÃO AMBIENTAL}

Uma das características marcantes na modernidade é a aliança entre a ciência e o processo produtivo industrial. Dias (200 I) afirma que essa articulação entre indústria e ciência resulta do progresso científico, crescimento da mobilidade pessoal, crescimento da produção industrial, vertiginosa ampliação dos assentamentos humanos, nas cidades, determinando amplas e profundas mudanças nas relações sociais e econômicas que geram, por fim, o processo de destruição ambiental.

Este processo de destruição ambiental também pode ser percebido pelos seus sintomas ${ }^{5}$, ou seja, os chamados problemas ambientais que são: efeito estufa; buraco na camada de ozônio; alterações na superfície da terra; exacerbações das mudanças climáticas; desflorestamento; queimadas; erosão do solo; areificação/ desertificação; destruição de habitats; perda da biodiversidade; poluição; escassez de água potável; erosão; perda da diversidade cultural e exclusão social.

5. Esse diagnóstico pode ser encontrado de forma mais detalhada em sítios de Organizações Governamentais e Não Governamentais, como Relatório Planeta Vivo 20 I 0: Biodiversidade, biocapacidade e desenvolvimento (POLLARD, 20I0). 
A diversidade de problemas ambientais mobiliza diferentes áreas do conhecimento na busca por soluções técnicas e científicas, assim como também mobiliza diversos setores de trabalho. Neste sentido, são sugeridas ações que buscam soluções práticas e teóricas para os problemas ambientais de diversas áreas simultaneamente. Entre essas ações, Dias (200 I) destaca a Educação Ambiental como uma possibilidade no campo da educação, com objetivo de proporcionar conhecimento sobre o meio ambiente e alterar a atual relação de consumo exacerbado e reestabelecer a relação de destruição entre ser humano e natureza.

Compreendemos que a Educação Ambiental é o resultado de um processo político sensível aos problemas ambientais, estando presente em espaços variados como o meio escolar e não escolar com orientações e diretrizes internacionais, nacionais, regionais e locais. Essas orientações e diretrizes da Educação Ambiental aparecem no Brasil a partir da Constituição de 1988 (BRASIL, 1988).

Analisando o âmbito escolar, em todos os níveis no mundo e no Brasil, as diretrizes da Educação Ambiental vêm buscando organizar o processo pedagógico para formar pessoas com atitudes conscientes ${ }^{6}$ em relação ao seu meio ambiente, através da aquisição de conhecimentos, valores, habilidades, experiências e determinação, visando atitudes e resoluções de problemas ambientais. O processo pedagógico da Educação Ambiental se organiza a partir de princípios sistematizados pelo Tratado para as Sociedades Sustentáveis e Responsabilidade Global ${ }^{7}$ e pressupõe:

- Ter como base o pensamento crítico e inovador, promovendo a transformação e a construção da sociedade;

- Ser individual e coletiva, com propósito de formar cidadãos com consciência local e planetária, respeitando a autodeterminação dos povos e a soberania das nações;

6. No sentido comum estar ciente dos próprios estados, percepções ideias, sentimentos, volições. Atenção aos seus modos de ser e suas ações. Na filosofia contemporânea, em geral, é o princípio criativo da realidade e ao mesmo tempo manifesta e revela imediatamente essa realidade no interior do homem. Para outros aprofundamentos ver: Abbagnano, (2000).

7. Esses tratados foram construídos especialmente na Jornada Internacional de Educação Ambiental realizada no Fórum Global em 1992 no Rio de Janeiro, organizada pelo Conselho Internacional de Educação de Adultos com apoio de organizações nãogovernamentais, como o Serviço Universitário Mundial e a Associação Internacional de Educação Comunitária. 
- Envolver uma perspectiva holística, enfocando a relação entre o ser humano, a natureza e o universo de forma interdisciplinar;

- Estimular a solidariedade, a igualdade e o respeito aos direitos humanos, valendo-se da estratégia democrática e interação entre as culturas;

- Integrar conhecimentos, aptidões, valores, atitudes e ações;

- Converter cada oportunidade em experiências educativas das sociedades sustentáveis;

- Ajudar a desenvolver uma consciência ética sobre todas as formas de vida com as quais compartilhamos este planeta, respeitar seus ciclos vitais e impor limites à exploração dessas formas de vida pelos seres humanos.

No Brasil, um dos impactos deste tratado, foi a formulação da Política Nacional de Educação Ambiental (BRASIL, 1999), que propõe assegurar, no âmbito educativo, a integração equilibrada das múltiplas dimensões da sustentabilidade - ambiental, social, ética, cultural, econômica, espacial e política - ao desenvolvimento do país. Chama atenção também para uma educação que tenha como objetivo a formação da sociedade com base em uma melhor qualidade de vida para toda a população brasileira, por intermédio do envolvimento e participação social na proteção e conservação ambiental e da manutenção, em longo prazo, dessas condições de vida.

As contribuições da Educação Ambiental são diversas em vários níveis de formação escolar e não escolar, reconhecemos que ela abre possibilidades para mobilização de ações articuladas em áreas distintas, por isso não pode ser entendida como uma ação local, isolada e disciplinar. Neste sentido, estamos analisando os fundamentos e princípios para pensar uma Formação de Professores em Educação Física voltada para uma formação ambientalista, ou seja, uma formação articulada com a busca por soluções ambientais no campo da educação. Para isto, buscamos analisar algumas características de limites e possibilidades da Formação de Professores em Educação Física.

\section{LIMITES DA FORMAÇÃO DE PROFESSORES EM EDUCAÇÃO FÍSICA}

O campo de Formação de Professores em Educação Física apresenta algumas particularidades, das quais serão destacadas apenas aquelas que, no nosso ponto 
de vista, são limitadoras ao trabalho pedagógico relacionado a Educação Ambiental: fragmentação do curso do conhecimento nos cursos de formação de professores em Educação Física; e o caráter esportivo nas disciplinas.

A primeira diz respeito à Fragmentação dos cursos de Educação Física. Nas diretrizes da Educação Ambiental o que se propõe é que seja tratada de forma Transversal e Interdisciplinar ${ }^{8}$. Pois se reconhece a necessidade de entender no processo pedagógico o meio ambiente como um todo. As atividades das disciplinas devem ser simultâneas em diversos campos e áreas do conhecimento, e devem estar articuladas em uma temática, projeto ou conteúdo.

$\mathrm{Na}$ Educação Física a realidade, neste sentido, mostra uma contradição. Os cursos de Formação de Professores em Educação Físca organizados em disciplinas isoladas, com horas e espaços pré-determinados, fragmentadas e distintas, representam uma organização curricular fragmentada. Para alguns autores como Kunz et al. (1997), Taffarel e Lacks (2007) Rezer (2007) a fragmentação do conhecimento na formação de professores em Educação Física reflete também a dicotomia mentecorpo, trabalho manual e intelectual, a teoria e a prática. Compreendemos que essa contradição da organização curricular fragmentada não foi ainda superada, apesar de reformas curriculares que foram implantadas a partir da resolução 03/87 (CONSELHO NACIONAL DE EDUCAÇÃO, 1987) no campo da Formação Profissional.

O segundo ponto a ser analisado é sobre os conteúdos da Formação de Professores em Educação Física. Um dos princípios que a Educaçâo Ambiental apresenta é a valorização da diversidade cultural. As diretrizes da Educação Ambiental, em geral, nos orientam para pensar em uma valorização da produção cultural da vida cotidiana, buscando sentido e significado em cada momento em cada ato. E abre possibilidade para pensar a organização dos conteúdos, articulados com a realidade, na qual a construção do conhecimento é uma necessidade construída a partir dos problemas identificados no cotidiano da vida. Aspecto que contradiz a própria lógica acadêmica formal de organização na formação de professores burocrática, conteudista e fragmentada. Neste sentido, o que e como se conhece, passa a ser um complexo ${ }^{9}$ pedagógico, no qual há uma necessária integração entre a realidade,

8. Segundo o PCN: A interdisciplinaridade supõe um eixo integrador, que pode ser o objeto de conhecimento, um projeto de investigação, um plano e intervenção. Nesse sentido, ela deve partir da necessidade sentida pelas escolas, professores e alunos de explicar, compreender, intervir, mudar, prever, algo que desafia uma disciplina isolada e atrai a atenção de mais de um olhar, talvez vários (BRASIL, 1997, p. 32).

9. De acordo com o autor Pistrak (2000) o conhecimento na escola é organizado pelo sistema dos complexos, no qual a realidade é entendida como possibilidade de gerar temas problemas para 
as conquistas e as dificuldades do seu cotidiano de vida e, também, pedagógico. $\bigcirc$ que se conhece passa a ser a própria produção cultural, na qual o esporte, também é um elemento a ser valorizado, mas não apenas ele.

Neste aspecto entendemos que a relevância ao conteúdo esportivo deve ser também analisada, já que percebemos na história, na escola e na formação de professores grande influência esportiva (DOMINGUES, 200 I). Para alguns autores a relação esporte e natureza podem ser desastrosas.

Costa (1997), por exemplo, organizou um livro sobre Desporto e Meio Ambiente reunindo várias áreas do conhecimento em torno da problemática ambiental em relação ao esporte. Deste livro destacamos autores como Atkinson, Eckard, Jãgemann, Piageassou, Rittner que analisam de modo particular os aspectos pedagógicos, sociais, culturais, políticos e éticos da relação esporte e natureza. Eles de modo geral afirmam, por exemplo, que há destruições dos espaços naturais e do próprio ser humano nas práticas esportivas que o esporte é potencialmente alienador ${ }^{10}$ do ser humano e dele em relação ao meio ambiente; que o esporte enquanto uma atividade esportiva exige instalações e mega instalações " devastando diretamente a natureza; e que o esporte é um fenômeno que valoriza produtos diretos e indiretos da indústria cultural.

Destes aspectos, destacamos a alienação como central na aproximação da Formação de Professores em Educação Física e a Educação Ambiental. Um dos princípios da Educação Ambiental chama atenção para o processo pedagógico que proporcione a conscientização ambiental. A conscientização é uma das principais estratégias para mudança de atitude do ser humano perante a natureza. Faz parte do objetivo geral do processo pedagógico da Educação Ambiental, a conscientização de si e do meio. É necessário com a conscientização ambiental saber o que se faz como se faz e quais são os impactos destas ações para o meio no local e no global. Ela está relacionada diretamente as transformações do ser sujeito e subjetivo e do sistema social, de um modo dialético entre as mudanças individuais e as estruturais sócio-econômicas. Os estudos de Leis (1999) demonstram que as condições de vida no capitalismo são insustentáveis pelas suas próprias características o que exige pensar a Educação Ambiental como um campo de possibilidades para mudanças

estudos no processo de formação humana, os fenômenos nesta perspectiva se apresentam não de forma unitária isolada, mas por uma relação de complexos temáticos da realidade.

10. No Brasil também temos o autor Vaz (1999) que faz uma análise mais extensa e profunda sobre esse assunto não se encerrando apenas neste aspecto.

I।. O relatório técnico científico de Taffarel (1999) traz uma síntese sobre os estudos do Jurgen Diekert sobre o impacto na natureza das construções esportivas. 
simultâneas entre o indivíduo e a sociedade. Portanto, o esporte deve ser problematizado na Formação de Professores em Educação Física de modo que proporcione possibilidades de conscientização, negando a simples reprodução técnica de gestos, de padrões individuais e sociais e o incentivo ao consumo exacerbado.

\section{ALGUMAS POSSIBILIDADES}

Pensamos que é necessário entender os limites da área da Educação Física para estabelecer parâmetros da realidade da formação de professores e com isso indicar possibilidades para um trabalho pedagógico entre a Educação Ambiental e a Formação de professores em Educação Física.

Essas possibilidades foram analisadas a partir dos limites sobre a fragmentação do conhecimento nos cursos de Formação de Professores em Educação Física, e sobre o caráter esportivo nas disciplinas.

Em relação à fragmentação do conhecimento, por exemplo, buscamos orientações na organização do currículo de formação por complexos temáticos. A autora Taffarel e Lacks (2007) contribuiu com essa perspectiva analisando os conteúdos como sistemas de complexos que devem ser apreendidos, vividos e experimentados a partir da vida real. Para nós, isso é relevante quando se quer pensar em uma possível relação entre Educação Ambiental e Formação de Professores em Educação Física. Isto implica em uma desconstrução do pensamento disciplinador, fragmentador e simplificador para outro espaço pedagógico em que o mundo seja potência e possibilidade de construção do conhecimento, pela relação do ser humano com a natureza, a partir do seu meio e da sua produção cultural.

A cultura é outro ponto relevante quando pensamos nas possibilidades. O conceito de cultura é entendido, aqui, como um processo histórico, criativo e livre, que se expressa na relação do cotidiano ser humano e natureza. Para Gadotti (2000), a Educação Ambiental deve atuar padagogicamente para alterar a cultura, o que significa primeiramente reconhecer as atuais relações dos seres humanos entre si e com a natureza, identificá-las como predatórias para posteriormente buscar relações menos degradantes entre o ser humano e natureza.

Portanto, na perspectiva ambiental é que a Educação Física oriente seu trabalho para a valorização da produção cultural do cotidiano, de forma crítica, problematizando o conhecimento, a partir de elementos da cultura, ou seja, do que foi construído historicamente, o que faz sentido e o que valoriza a vida. Também encontramos contribuições pedagógicas do Kunz (2003) que destacam a importância da vivência e experiência no mundo, proporcionando um 
processo pedagógico de conhecimento do seu meio e de autoconhecimento. Essa é uma possibilidade de trabalhar a Educação Ambiental na Formação de Professores em Educação Física. Para a Educação Ambiental, valorizar a cultura significa valorizar a vida nas suas diversas formas de interação com o meio e não apenas limitando-se em modelos de modalidade esportiva, fragmentada, reprodutiva e técnica.

Compreendemos que a organização dos conteúdos das várias disciplinas no currículo de Formação de Professores em Educação Física pode ser construída a partir da aproximação com a realidade da docência. A forma de organizar o trabaIho pedagógico encontra nas atividades de ensino, pesquisa e extensão condições favoráveis para estudar, aprofundar e construir esses conteúdos. Portanto, estamos falando de conteúdos reconhecidos no cotidiano, na cultura, e que proporcionam o conhecimento do ambiente em que se vive e também o conhecimento da especificidade da Educação Física. Desta forma os fundamentos políticos, fisiológicos, sociológicos e pedagógicos de conteúdos culturais como danças, folguedos, jogos, ginástica, brincadeiras e atividades esportivas são trabalhados para proporcionar o conhecimento da Educação Física e do ambiente.

Essa aproximação da Formação de Professores em Educação Física com a realidade do cotidiano proporciona o contato com problemáticas significativas do local que podem ser articuladas com diversas áreas do conhecimento. E aqui nos referimos a dois princípios da Educação Ambiental, um sobre a necessidade de conhecer o local e planetária e o outro princípio da interdisciplinaridade. Este contato interdisciplinar pode ser estabelecido junto aos trabalhos de docência da Educação Física na extensão, pois nas atividades de extensão universitária é possível entender o conteúdo como um complexo da realidade que articula diversas áreas do conhecimento.

\section{CONSIDERAÇÕES FINAIS}

Buscamos analisar neste texto como pode ser a relação entre a Educação Ambiental e a Formação de Professores em Educação Física. Reconhecemos que é crescente a participação do campo profissional da Educação Física em diversos espaços e isto significa, para nós, que este é um tema relevante para o desenvolvimento de pesquisas e estudos no campo da formação de professores.

Neste campo da formação, destacamos as diretrizes da Educação Ambiental como possibilidades de aproximação com a formação de professores em Educação Física. Para essa aproximação analisamos a importância da Educação Ambiental 
enquanto um movimento político ambiental e destacamos suas diretrizes. No campo da Educação Física analisamos algumas características da realidade dos cursos de professores que são limitadoras para desenvolver um trabalho pedagógico com a Educação Ambiental. Destacamos as seguintes características: fragmentação do curso do conhecimento nos cursos de formação de professores em Educação Física; e o caráter esportivo nas disciplinas.

Esses limites característicos da realidade dos cursos de professores em Educação Física são relevantes para analisar quais as possibilidades de aproximações com a Educação Ambiental. Compreendemos que estas possibilidades estão na organização do trabalho pedagógico e na formação de professores com base no ensino, pesquisa e extensão buscando trabalhar os conteúdos como sistema de complexos que não só valoriza os conteúdos esportivos, mas sim valoriza a produção cultural do cotidiano.

Por fim, consideramos que a Educação Física pode estar, enquanto um campo de atuação profissional, contribuindo com ações ambientais, alterando a relação ser humano e natureza, pelas suas próprias especificidades. E indicamos que esta relação pode ser pensada na Formação de Professores quando se aproxima aos princípios da Educação Ambiental e um dos caminhos é encontrar possíveis soluções para os limites da realidade, em geral, trazidos pela destruição ambiental, e em específico pela fragmentação do conhecimento na formação de professores e a negligência do trato com o conhecimento sobre Meio Ambiente na formação de professores em Educação Física.

Environmental education and physical education: possibilities for teacher education

ABSTRACT: This work is among those studying Environmental Education and Physical Education. Through theoretical analysis of documents, books and seek evidence in the field of environmental education goals, principles and guidelines constructed historically, and identified in Teacher Education in Physical Education the limits and possibilities for developing pedagogical work in accordance with the principles of Environmental Education. Indicate that this approach between the Environmental Education can be thought of from the critical understanding of content and specific forms of physical education

KEYWORDS: Environmental education; teacher education; physical education; curriculum guidelines. 


\section{La educación ambiental y la educación física: posibilidades de formación de docentes}

RESUMEN: Este trabajo es uno de los cursantes de Educación Ambiental y la Educación Física. A través del análisis teórico de los documentos, libros y artículos en el ámbito de los objetivos de la educación ambiental, los principios y directrices construida históricamente, y determinó la formación del profesorado de Educación Física de los límites y las posibilidades de desarrollar el trabajo pedagógico, de conformidad con los principios de Educación Ambiental. Indicar que este acercamiento entre la educación ambiental y formación del profesorado en Educación Física se puede considerar a partir de la comprensión crítica de los contenidos y las formas específicas de la educación física.

PALABRAS CLAVE: Educación ambiental; formación de docentes; la educación física; lineamientos curriculares.

\section{BIBLIOGRAFIA}

ABBAGNANO, N. Consciência. In: ABBAGNANO, N. Dicionário de filosofia. São Paulo: M. Fontes, 2000. p. 326

BRASIL. Constituiç̧ão (1 988). Constituição da República Federativa do Brasil: promulgada em 5 de outubro de 1988. Disponível em: < http://www.planalto.gov.br/ccivil_03/constituicao/ constitui\%C3\%A7ao.htm>Acesso em: 10 mar. 2009.

BRASIL. Ministério da Educação. Conselho Nacional de Educação. Câmara de Educação Básica. Parecer CEB n. 4/98. Diretrizes Curriculares Nacionais para o Ensino Fundamental. Brasília, DF: MEC/CNE, 1998. Disponível em: < http://portal.mec.gov.br/cne/arquivos/pdf/ pceb04_98.pdf> Acesso em: 20 dez. 2009.

BRASIL. Lei n. 9.795, 27 abr. 1999. Dispõe sobre a Educação Ambiental, institui a Política Nacional de Educação Ambiental e da outras providências. Diário Oficial [da] União, Brasília, 28 abr. 1999. Disponível em: < http://www.planalto.gov.br/ccivil_03/leis/9795.htm> Acesso em: 20 mar. 2009.

BRASIL. Ministério da Educação Secretaria de Educação Fundamental. Parâmetros Curriculares Nacionais: Educação Física / Secretaria de Educação Fundamental. Brasília: MEC/SEF, 1997. 96p. Disponível em: <http://portal.mec.gov.br/seb/arquivos/pdf/ivro0 I.pdf>. Acesso em: 20 mar. 2009.

CONSELHO NACIONAL DE EDUCAÇÃO. Fixa os mínimos de conteúdo e duração a serem observados nos cursos de graduação em Educação Física (Bacharelado e/ou Licenciatura Plena). Resolução n. 03, de 16 de junho de 1987. Disponível em: < http://www.apefsc.com. br/index.php?codpagina=00023984> Acesso em: 22 dez. 2009. 
COSTA, L. P. (Org.). Meio Ambiente e Desporto. Uma Perspectiva Internacional. Faculdade de Ciências do Desporto e Educação Física, Portugal: Universidade do Porto, 1997.

DIAS, G. F. Educação Ambiental. Princípios e Praticas. $6^{\circ}$ ed. Revisado e Ampliado pelo autor. São Paulo: Gaia, 2001.

DOMINGUES, S. C. TAFFAREL. C. NZ. Ecoesporte: indicações curriculares para a formação de professores. In. REUNIÃO ESPECIAL DA SBPC/ SOCIEDADE BRASILEIRA PARA O PROGRESSO DA CIÊNCIA E INSTITUTO NACIONAL DE PESQUISA NA AMAZÔNIA, 7., 200 I, Manaus, AM. Anais..., Manaus. Editora UFAM, 200 I, p. 23-28.

GADOTTI, M. Pedagogia da terra. São Paulo: Petrópolis, 2000. (Série Brasil Cidadão).

GOHN, M. G. Teoria dos Movimentos Sociais. Paradigma Clássico e Contemporâneo. 5 ed. São Paulo: Edições Loyola, 2006.

INÁCIO, H. L. D. Lazer, educação e meio ambiente: uma aventura em construção. Revista Pensar a Prática, Goiânia, v. 9, n. I, 45-63, jan./abr., 2006. Disponível em: <http://www. scielo.br>. Acesso em: 20 set. 2008.

KUNZ, E. et al. Pensando o Currículo Coletivamente: Parceria UFSC - PMF. In: SEMINÁRIO DE EDUCAÇÃO FÍSICA ESCOLAR E ENSINO MÉDIO, 4., 1997, São Paulo. Anais... São Paulo: Editora da USP, 1997. v. I. p. 98-106.

KUNZ, E. Transformação didático-pedagógica do esporte. ljuí: Unijuí, 2003.

LEFF, E. Saber Ambiental: sustentabilidade, racionalidade, complexidade, poder. Tradução Lúcia Mathilde Endlich Orth. Petrópolis, Rio de Janeiro: Vozes, 2001.

LEIS, H. A Modernidade Insustentável: as críticas do ambientalismo à sociedade contemporânea. Petrópolis, Rio de Janeiro: Vozes, 1999.

LEITE, D. M. T.; CAETANO C. A. Educação física, esporte e lazer na natureza: preservação, modismo, apologia. Será tudo isso? Motrivivência, Florianópolis, ano 16, n. 22, p. I37-143, jun. 2004.

MARINHO, A.; INÁCIO, H. L. D. Educação Física, meio ambiente e aventura: um percurso por vias instigantes. Revista Brasileira de Ciências do Esporte, Campinas, v. 28, n. 3, p. 55-70, jul./set., 2007.

PISTRAK, M. M. Fundamentos da escola do trabalho. São Paulo: Expressão Popular, 2000.

POLLARD. D. (Org.) Relatório Planeta Vivo 2010: Biodiversidade, biocapacidade e desenvolvimento. Tradução Marsel de Souza. WWF Internacional, 20 I 0. Disponível em: <http:// assets.wwfbr.panda.org/downloads/08out10_planetavivo_relatorio2010_completo_n9.pdf $>$. Acesso em: 16 nov. 2010.

REZER, R; NASCIMENTO, J. As novas diretrizes curriculares a regulamentação e o processo de formação - apontamentos para o campo da Educação Física Brasileira. In: CONGRESSO 
BRASILEIRO DE CIÊNCIAS DO ESPORTE, I5, 2007, Recife. XV Anais..., Recife, UFPE, 2007. p. I-10. Disponível em: <http://www.cbce.org.br/cd/resumos//79.pdf>. Acesso em: 20 maio, 2009.

TAFFAREL, C. N. Z. Relatório técnico-científico apresentado ao CNPq. Recife: Universidade Federal de Pernambuco, 1999. Mimeografado.

TAFFAREL; C. N. Z.; LACKS, S. Formação Humana e Formação de Professores: Contribuições para construção do projeto histórico socialista. In: CONGRESSO BRASILEIRO DE CIÊNCIAS DO ESPORTE, 15., 2007, Recife. Anais..., Recife, 2007. Disponível em: < http:// www.cbce.org.br/cd/resumos//88.pdf>. Acesso em: 19 mai. 2009.

VAZ, A. F. Treinar o corpo, dominar a natureza: notas para uma análise do esporte a partir do treinamento corporal. Cadernos Cedes, Campinas, n. 48, p. 89-108, ago. 1999.

Recebido: 20 set. 2009 Aprovado: 10 mar. 2011

Endereço para correspondência:

Soraya Corrêa Domingues

Rua Maranhão, n. I I I0, Água Verde, Curitiba/PR CEP: 806।0-00। 